\title{
Detection of Saline Groundwater Bodies between the Dead Sea and the Mediterranean Sea, Israel, Using the TDEM Method and Hydrochemical Parameters
}

\author{
Uri Kafri • Mark Goldman • Eldad Levi • Stuart Wollman
}

Received: 20 January 2014 / Accepted: 5 March 2014 / Published online: 29 April 2014

(C) Springer International Publishing Switzerland 2014

\begin{abstract}
A Time Domain ElectroMagnetic (TDEM) survey coupled with hydrogeological information was carried out along the Be'er Sheva valley between the Mediterranean Sea and the Dead Sea base levels, aiming to obtain the subsurface distribution of the different fresh and saline water bodies. Hydrochemical considerations and previous TDEM results hinted that the previously accepted model of an upper fresh water body underlain by solely Dead Sea (R-type) brines in the east and C-type brines in the west does not match the actual observations. Thus, the suggested working hypothesis of additional intruding seawater from the Mediterranean Sea to the Dead Sea base level was checked by the TDEM method. The results, indeed, exhibit an upper high resistivity fresh water body, an underlying low resistivity brine body and a moderate resistivity body in between. The origin of this body is not uniquely determined based on the geophysical measurements alone. Analysis of borehole data testifies that hydrochemical parameters of the body cannot be solely interpreted as a mixture of the above two end members, but rather calls for an additional contribution of intruding seawater. The suggested configuration consists of an upper fresh water body flowing to both base levels in the west and the east. Underneath there is a saline body resulting from seawater intrusion reaching from the Mediterranean to the Dead Sea base level. At the bottom there is a third body of the westward density driven Dead Sea brine. The entire configuration is supported by results of subsurface flow modeling.
\end{abstract}

Keywords Seawater intrusion · Endorheic base levels · TDEM · Geochemistry

U. Kafri $(\square) \cdot$ S. Wollman

Geological Survey of Israel, Jerusalem, Israel

e-mail: uri.kafri@gsi.gov.il

M. Goldman • E. Levi

Geophysical Institute of Israel, Lod, Israel

M. Goldman • E. Levi

University of Haifa, Haifa, Israel 


\section{Introduction}

The different deep-seated saline sources of the Be'er Sheva valley, between the Mediterranean Sea and the Dead Sea Rift (DSR) (Fig. 1), were analyzed and discussed, among others, by Starinsky (1974), Nativ (1984) and Fleischer et al. (1977). A basic distinction between the different saline brine types was proposed by Starinsky (1974) and was adopted in subsequent studies. The two basic types of brines proposed are: a) C-type brine with a $\mathrm{rNa} / \mathrm{rCl}$ (hereafter $\mathrm{Na} / \mathrm{Cl}$ ) ratio similar to the marine one $(0.82-0.86)$ found in the western part of the study area; and b) R-type (rift-type) of a Ca-chloride brine with $\mathrm{Na} / \mathrm{Cl}$ ratios lower than the marine ones, which originates from the DSR. An additional component of the system is the slightly brackish paleo water of the Nubian sandstone aquifer. This water type is found mostly in the eastern portion of the study area with a $\mathrm{Na} / \mathrm{Cl}$ ratio around 1 (Issar et al. 1972).

A further modeling study by Stanislavsky and Gvirtzman (1999) demonstrated both the distribution of the above brine types below the fresh groundwater system in the study area. They exhibited the C-type in the west and the R-type, which is density driven underneath them from the DSR westward. It is important to note that according to this model the fresh groundwater system in the eastern part of the study area, close to the DSR, directly overlies the intruding Dead Sea brine (hereafter DSB) of the R-type.

Shallow TDEM measurements in the Dead Sea coastal plain and adjacent to its shoreline indeed succeeded in detecting the interface between a fresher, relatively higher electric resistivity water body, and a DSB of a very low resistivity (Kafri et al. 1997).

A further deep TDEM survey, on the other hand, carried out west of and adjacent to the Dead Sea coastal plain exhibited a different configuration (Levi et al. 2008). The upper, high resistivity water body was found to be underlain by a water body with resistivities higher than those expected in the case that it represents a DSB, at the appropriate depth calculated by the Ghyben-Hertzberg approximation. This could indicate the existence of a triple water body configuration, namely the existence of an intermediate saline water body between the upper fresh water body and the lower DSB body.

The Be'er Sheva morphotectonic valley between the Mediterranean Sea and the DSR consists of a relatively shallow and rather fresh groundwater system, which is underlain by deeper saline water bodies or systems. However, the amount of direct hydrochemical data regarding these bodies obtained from deep wells, as to their type, origin and vertical distribution is rather limited.

A long term experience was gained in Israel in using the time domain electromagnetic (TDEM) method as a tool to detect intruding seawater or brines to coastal aquifers and to define the interface depth between the overlying fresh water bodies and the underlying saline ones (Goldman et al. 1989, 2003; Kafri and Goldman 2006). Most of the experience was gained in the rather shallow Mediterranean granular (sand, calcareous sandstone) coastal aquifer with fractional porosities varying between 0.2 and 0.4 . It was found that the resistivity of the seawater intruded portion of this aquifer is between 1 and $3 \Omega$-m with the mean value of approximately $1.4 \Omega-\mathrm{m}$ (Goldman et al. 1989). The Dead Sea coastal aquifer that is intruded by the concentrated DSB exhibits on the other hand resistivities well below $1 \Omega-\mathrm{m}$ (Kafri et al. 1997).

Concerning the seawater intruded carbonate aquifers in Israel, less geo-electric information was obtained. It was found, however, that when intruded by normal sea water they exhibit higher resistivities as compared to the granular aquifers (approximately $5 \Omega-\mathrm{m}$ ). This difference was attributed to their typical lower porosities between 0.05 and 0.1 (Goldman and Kafri 2004, 2006; Kafri and Goldman 2005). 
Fig. 1 Location map of the study area

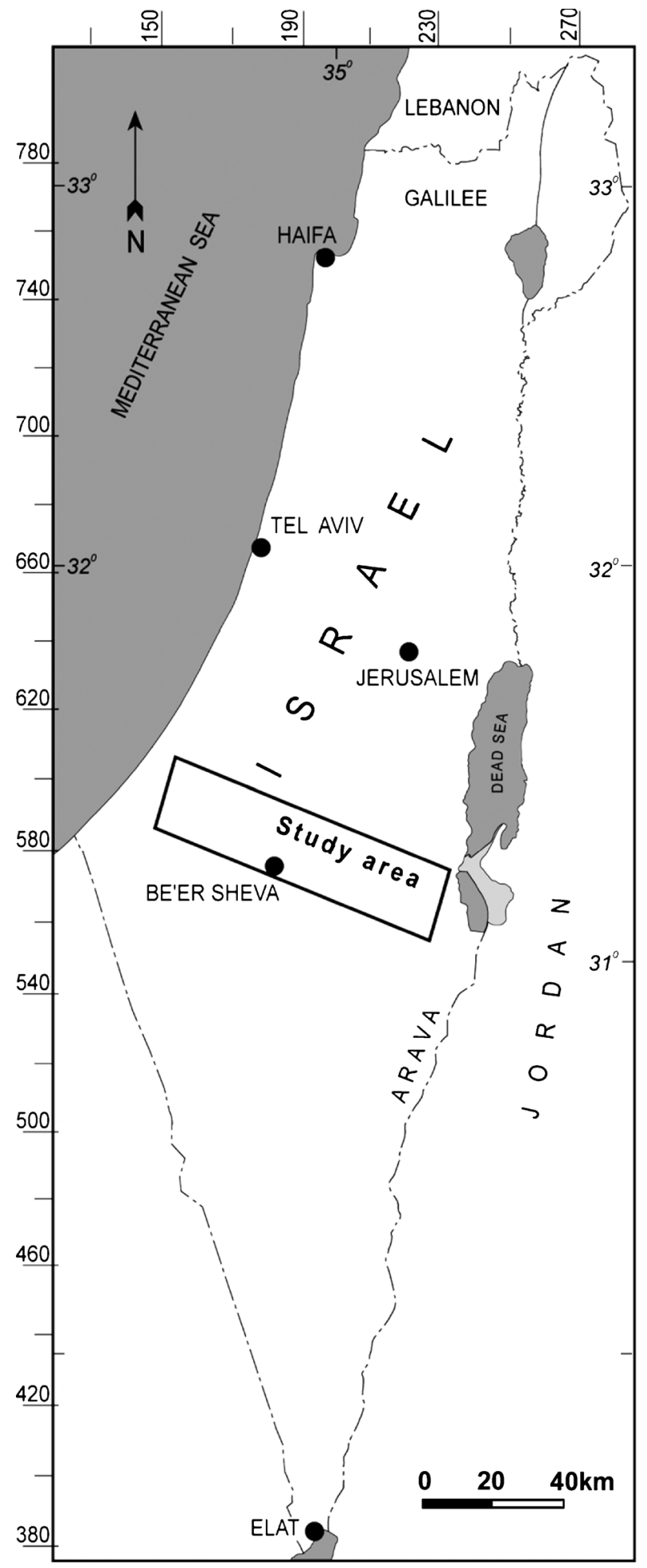

Springer 
The rather scarce information, regarding the resistivities of the deep aquifers that occupy saline waters, was obtained in deep TDEM surveys carried out in northern Israel between the Mediterranean and the Sea of Galilee (Kafri et al. 2007), as well as in the Arava Valley between the Dead Sea and the Gulf of Elat (Kafri et al. 2008), and in the Judea Desert, west of the Dead Sea (Levi et al. 2008).

The objective of the present study was to execute deep TDEM measurements along the study area and to compare them with hydrochemical results obtained from wells. The combination of both should help in delineating the different water bodies, detecting the interfaces between them and obtaining their vertical distribution.

\subsection{Geological and Hydrogeological Background}

The study area extends on both sides of the regional groundwater divide between the Mediterranean and the Dead Sea base levels. The regional Judea Group aquifer (Table 1) is being recharged mostly in the mountains north of the study area and the groundwater flows southward to the Be'er Sheva valley and from there to both base levels in the west and the east. In addition, The Lower Cretaceous and the Hatira Formation aquifers (Table 1) underneath it, contain brackish water arriving from the south, that were mostly recharged to the system during the last glacial period (Issar et al. 1972).

The Be'er Sheva valley is a west-east directed morphotectonic valley between the Mediterranean base level and the DSR endorheic base level. It was, as such, subjected in the past to Neogene sea ingression from the west. The valley is obliquely crossed and underlain by a series of NE-SW directed anticlines and synclines of the Syrian Arc system (Shahar 1994). The stratigraphic sequence (Table 1) of Triassic to Quaternary age is exposed in the valley and its southern and northern margins and was penetrated by wells in the study area.

Table 1 The geological units that constitute the subsurface of the study area and a legend to Figs. 4, 5, and 6

\begin{tabular}{lll}
\hline Symbol & Age/formation & Description \\
\hline $\mathrm{Pl}$ & Quaternary & Sandstones, calcareous sandstones and clays \\
Saq. & Neogene & Mostly shales \\
$\mathrm{E}$ & Eocene & Mostly chalks and limestones \\
$\mathrm{S}$ & Senonian & Mostly chalks \\
$\mathrm{C}-\mathrm{T}$ & Cenomanian-Turonian & Mostly carbonates of the Judea Group \\
$\mathrm{Ty}$ & Talme Yaffe Fm. & Mostly marls and limestones \\
$\mathrm{LC}$ & Lower Cretaceous & Mostly limestones and marls \\
$\mathrm{H}$ & Hatira Fm. & Mostly sandstones \\
$\mathrm{J}$ & Jurassic & Mostly limestones \\
$\mathrm{K}$ & Kidod Fm. & Mostly shales with abundant sulfides \\
$\mathrm{Tr}$ & Triassic & Mostly carbonates and evaporites \\
$\mathrm{Pal}$ & Paleozoic & Carbonates, shales and sandstones \\
$\mathrm{LOC}$ & Loss of circulation & \\
10 & Salinity $(\mathrm{g} / \mathrm{l}), \mathrm{Na} / \mathrm{Cl}$ ratio around the marine one \\
100 & Salinity $(\mathrm{g} / \mathrm{l}), \mathrm{Na} / \mathrm{Cl}$ ratio below the marine one \\
$\nabla$ & Water table & \\
\hline
\end{tabular}


The existence of endorheic terminal base levels, which are located considerably below sea level and are subjected to subsurface seawater intrusion, has been investigated by Kafri and Arad (1979) in the case of the northern portion of the DSR base level. The investigated configuration and mechanism were based on the following: a) the groundwater system is connected to the Mediterranean Sea; b) a significant elevation difference exists between the sea and the base level below sea level; c) a hydrological continuity exists between both; and d) a rather low groundwater divide coupled with a deep base of the groundwater system exists between both base levels. According to the Ghyben-Hertzberg approximation, this enables seawater intrusion across the divide to the lower base level.

The northern transversal morphotectonic valleys of Israel (Yizreel, Harod and Bet-Shean) were found to comply with the above described configuration. A further study (Kafri et al. 2007) supported the previous proposed model of the northern DSR base level by using deep TDEM measurements and hydrological modeling.

Kafri and Arad (1979) also assumed that the Be'er Sheva valley, between the Mediterranean Sea and the Dead Sea portion of the DSR base level also has a similar configuration, except that the system was considered to be blocked to the sea in the west by the semi-permeable Talme Yafe Formation. However, it was found that wells in the coastal plain in the Judea Group Aquifer, located to the east of and laterally to the Talme Yafe apparently confining sequence contain diluted seawater (Kafri and Goldman 2013). Namely, the Talme Yafe Formation does not act as a complete impermeable boundary to seawater encroachment. In addition, one can assume seawater encroachment along W-E transversal faults or along the margins of known Neogene channels both acting as hydrological conduits. The same situation can thus prevail also in the western margin of the Be'er Sheva valley. The valley, in addition, exhibits a rather wide equipotential divide at an elevation around $10 \mathrm{~m}$ above sea level (asl), between the Mediterranean and the DSR base levels, which declines steeply to the latter at the elevation of more than $400 \mathrm{~m}$ below sea level (bsl).

The same configuration of current seawater intrusion to endorheic base levels below sea level was suggested later on to additional cases in East and North Africa, as well as in North, Central and South America (Kafri 1984; Kafri and Yechieli 2010). A recent study, based on hydrological modeling, analyses two of the above cases, and the results support the proposed model (Kafri et al. 2013).

\subsection{Working Hypothesis}

The possibility of current seawater intrusion through the Be'er-Sheva valley to the Dead Sea base is based on the following assumptions:

a) The groundwater system between the Mediterranean coastal plain and the Dead Sea base level is continuous across most of the sedimentary succession of Paleozoic to Cretaceous age. b) As mentioned before (Kafri and Arad 1979), instead of a sharp groundwater divide, the study area consists of a wide equipotential water table surface at elevations roughly between 10 and $20 \mathrm{~m}$ asl between both base levels. Only east of approximately longitude 170 (Israeli grid) the water table drops sharply at a steep gradient to the Dead Sea base level presently below $420 \mathrm{~m}$ bsl. c) The assumed blockage of the Judea Group aquifer of the Yarqon-Taninim basin and the Lower Cretaceous formations in the west to the sea by the Talme Yafe Formation is re-considered and challenged herein. Based on indications from the western boundary of the Yarqon-Taninim basin, to the north of the study area, it is assumed that the groundwater system is not hermetically blocked to the sea. Somewhat diluted seawater with typical marine $\mathrm{Na} / \mathrm{Cl}$ ratios and $\delta^{18} \mathrm{O}$ values close to the marine one was encountered in boreholes in the central and northern part of the basin (Natural Resources Development 1999; Burg et al. 2006). 
Unfortunately, no such information exists in the western part of the study area. Similar to the north, it is assumed that seawater can also intrude the system here through the semi-permeable Talme Yafe Formation and/or through transversal faults that act as hydrological conduits. d) The previously proposed and accepted model of a fresh groundwater system that directly overlies C-type brines in the west and density westward driven DSB R-type brines in the east is not in agreement with some findings in the eastern part of the study area. The TDEM survey west of and adjacent to the Dead Sea (Levi et al. 2008) did not manage to detect sufficiently low resistivities expected for the DSB (Kafri and Goldman 2005) beneath the high resistivity (fresh water) body at the assumed calculated depth of a fresh water-DSB interface, as expected. Instead, more moderate resistivities were encountered there, indicative of a water body with a much lower salinity. One can assume that such a moderate resistivity body represents a fresh water-DSB transition zone, but a simple calculation based on hydrochemical parameters seems to reject such an assumption (as discussed in detail below).

\section{Methods}

In order to understand the type and genesis of the different, both fresh and saline, groundwater bodies in the study area and to delineate them, a TDEM campaign was planned and carried out, based on hydrogeological and the hydrochemical knowledge. All the relevant deep wells and shallower boreholes were examined as to their stratigraphic sequence and hydrogeological units. Two roughly WNW-ESE directed TDEM traverses were executed between the Dead Sea and the Mediterranean coastal plain. The traverses included 30 deep TDEM measurements

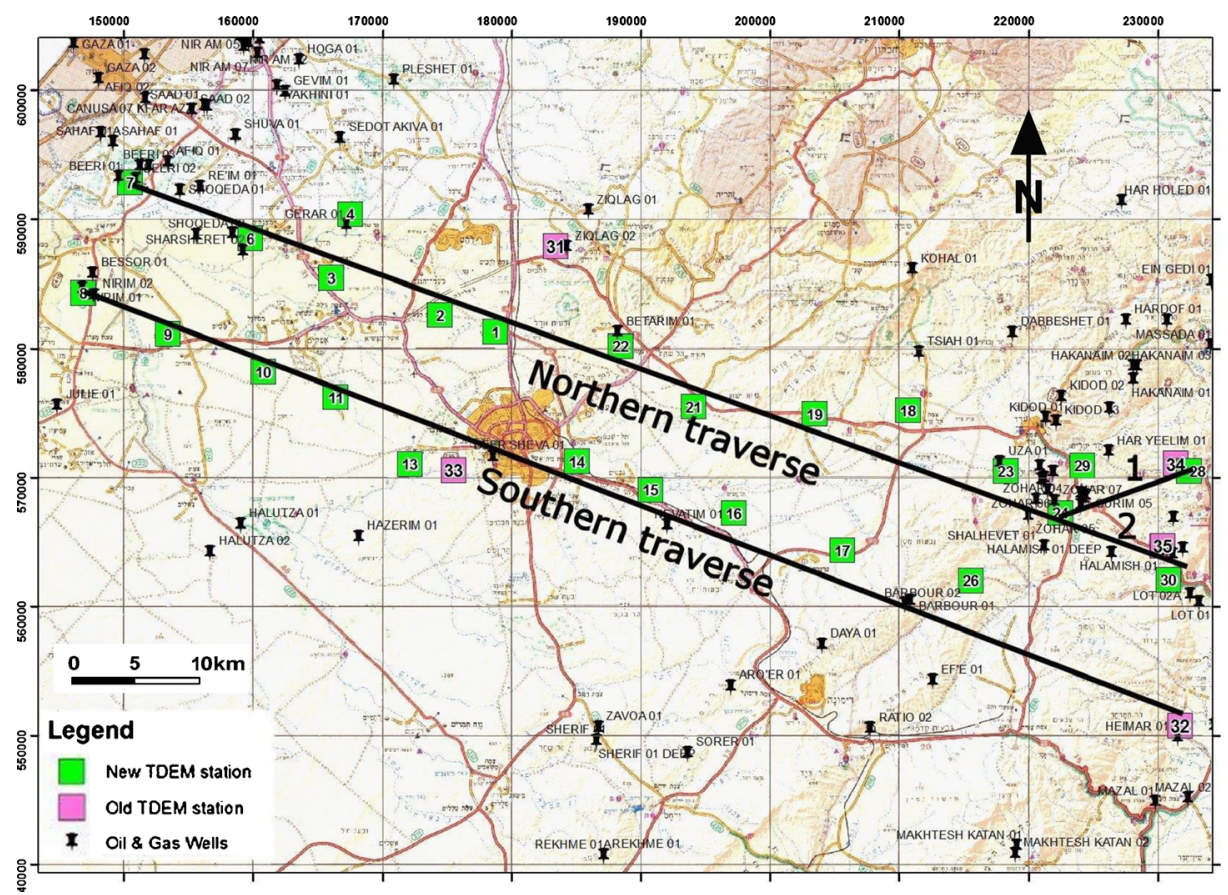

Fig. 2 Location map of the TDEM stations and the relevant oil wells. The TDEM measurements are grouped in two major traverses (northern and southern) 
located as close as possible to the existing wells for calibration and more reliable hydrogeological interpretation of the TDEM results (Fig. 2). The relevant geological units that constitute the sequence in the study area listed in detail in Table 1. Unfortunately, the TDEM traverses could not be extended to the proximity of the Mediterranean shoreline since the subsurface of the western coastal plain consists of a thick shale sequence of the Neogene Saqiye Group. From our previous experience, this is known to mask the underlying geoelectric structures. Thus, measurements were carried out only at sites where the thickness of the Saqiye Group does not exceed some $250 \mathrm{~m}$.

Thanks to the remoteness from industrial areas, the signal-to-noise ratios were generally high. Only at one measurement site, the data were so severely distorted by unknown sources that their interpretation was impossible. This measurement has been excluded from further analysis. The rest of the data exhibited a relative standard error of less than $3 \%$ up to the delay times of several hundred milliseconds, after which they were truncated and did not participate in the interpretation. The misfit error of the inversions has never exceeded the $3 \%$ level as well. Due to scarcity of borehole data, no a priori information has been used in choosing initial models. The latter were selected using the results of "smooth" (Occam's) inversions (Constable et al. 1987) by reducing the number of layers to a possible minimum. Although all inversion results were examined on the existence and the range of equivalence, the choice of a "true" model was based on the minimum misfit error only. Here also, this was caused by the lack of a priori information available. Since all the data were successfully interpreted in terms of 1-D models, no special analysis has been carried out with regard to possible 3-D effects.

The hydrochemical setup was re-analyzed. The hydrochemical database of subsurface water analyses was gathered from Starinsky (1974), Fleischer et al. (1977), Nativ (1984) and Stanislavsky and Gvirtzman (1999), as well as from the oil and water well archives of the Geological Survey of Israel. It is important to note that concerning oil wells, most of the samples were obtained by swab and drill stem test sampling. In several cases the same sampled interval yielded water of different salinity throughout the sampling procedure. This is most likely due to different proportions of dilution with fresher water from above. In these cases only the most concentrated samples were considered. The assumption behind is that these samples represent or are as close as possible to the authentic formation water. Likewise, they define the lowest concentration threshold value of that interval. Samples with known influence of acidification by hydrochloric acid, as reported by the drillers' reports, were rejected. Due to the scarcity of isotopic data, the hydrochemical interpretation was based mostly on the $\mathrm{Na} / \mathrm{Cl}$ ratio obtained from the available major element analyses, in order to define the origin of the different water bodies. Available $\delta^{18} \mathrm{O}$ results were also incorporated in order to define the origin of some samples.

In order to check the validity of the obtained interpretation the FeFlow simulator (Diersch and Kolditz 2002) was employed to exhibit the salinity distribution and the flow directions of the different water bodies in the study area.

\subsection{The TDEM Method}

\subsubsection{General}

The method described herein is a geophysical technique, which allows reconstructing the distribution of electrical resistivity/conductivity in the subsurface just below the measurement array located at the earth surface. It is also named the TEM (transient electromagnetic) method; both names will be used hereafter. 
In the course of this study, a special modification of the TEM method that uses very short transmitter (Tx)-receiver (Rx) separations (SHOTEM-short offset TEM), which could be significantly less than the depth to the target, was applied. The SHOTEM method provides the best lateral and excellent vertical resolution with regard to electrically conductive targets. It is practically insensitive, however, to resistive (particularly thin) structures and suffers from extremely low signal-to-noise characteristics

Taking into account that the hydrogeological target in the present study is highly conductive (saline groundwater) and the fact that the survey was planned to be carried out in a desert area characterized by a relatively low ambient EM noise, the choice of SHOTEM seems well justified. Among all existing SHOTEM systems, only the sufficiently deep ones such as the Russian Cycle-5M or the Canadian Geonics EM-42 could be applied to achieve the required depths of a few kilometers below the surface. As in previous similar TDEM surveys (e.g., Kafri et al. 2008), the Russian Cycle-5M system was used in the present study. Since the technical characteristics of the system have been elucidated in great details (e.g., Kafri et al. 2008), only the most relevant to the present study feature, namely the exploration depth of the SHOTEM method, is discussed below.

\subsubsection{Estimation of the CYCLE-5M Exploration Depth}

A quantitative assessment of the penetration depth is not as trivial as it seems at first sight. An example is shown herein by the interpreted model at TDEM station 1 (Fig. 3). The lowest interpreted boundary is located at a depth of approximately $1,100 \mathrm{~m}$. It is clear that the exploration depth of the system exceeds this depth, but there is no single commonly accepted way to quantitatively estimate this depth.

\section{TDEM-01}

a

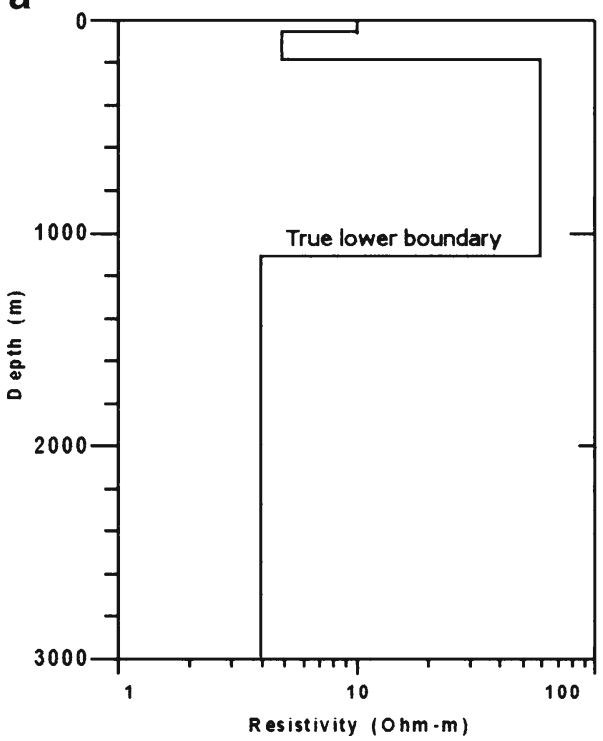

b

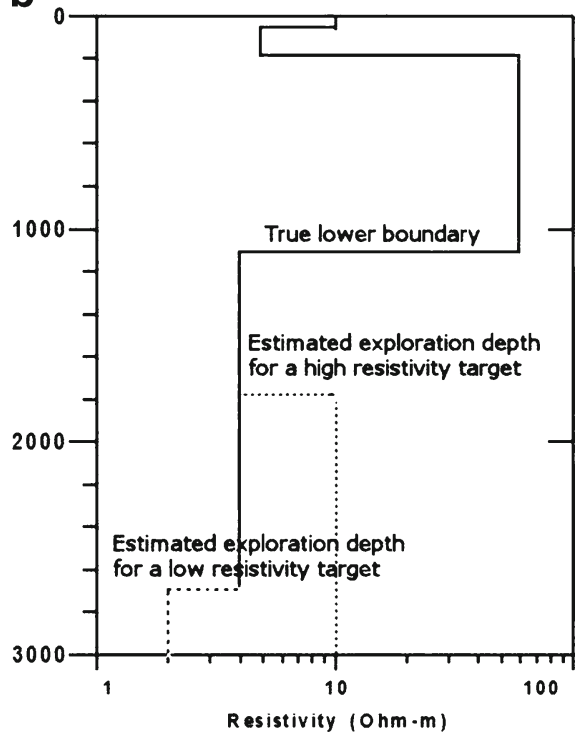

Fig. 3 Example of the estimated exploration depths in case of high and low resistivity targets at TDEM station 1. The solid lines represent true boundaries, the dashed ones represent estimated boundaries 
The following suggested procedure was solely used in the course of the present study:

1. An automated inversion of the collected data using a commercially available software such as TEMIX-XL (Interpex Ltd, USA) or Proba (Elta Geo, Russian Federation);

2. Addition of a fictitious layer, having a resistivity of the expected target, somewhere below the deepest actual boundary in the model obtained by the inversion;

3. Fixation of the resistivity of the fictitious layer/target and an additional inversion of the data using the modified interpreted model as a starting model for the inversion;

4. Repetition of the last two steps several times with different initial depths to the fictitious layer and selecting the solution with the minimum depth to the top of the fictitious layer;

5. Finally, this depth is considered as a maximum exploration depth of the system with regard to the required target (otherwise, the target would be detected by the first inversion of the collected data).

As mentioned before, an example of the application of the suggested assessment procedure applied to the data collected at TDEM station 1 is shown in Fig. 3. According to the interpretation, the deepest actual boundary is located at a depth of approximately $1,100 \mathrm{~m}$. A minimum possible depth to the fictitious layer having higher resistivity of approximately 10 $\Omega-\mathrm{m}$ is nearly $1,800 \mathrm{~m}$. This depth thus represents the maximum exploration depth of the Cycle-5M system at TDEM station 1, if the target is a thick layer, having a resistivity of $10 \Omega$ $\mathrm{m}$. If the target has a lower resistivity than that of the lowermost true layer, then the penetration depth might differ significantly. In the above considered example, the maximum exploration depth in the case of a low resistivity target $(2 \Omega-\mathrm{m})$ is approximately $2,700 \mathrm{~m}$.

By applying the above procedure to all the Cycle-5M data collected in the course of the present study, the estimated maximum exploration depth of the system was found to vary roughly between 1,000 and $3,100 \mathrm{~m}$ for a low resistivity target of approximately $2 \Omega-\mathrm{m}$, which assumingly represents the resistivity of carbonates saturated with brines at the above mentioned depths.

\subsection{Resistivity-Salinity Relationship}

Contrary to shallow (e.g., coastal) aquifers, estimating resistivities of deep aquifers is affected by additional factors such as temperature and pressure, which might complicate even very rough estimates based on the simplified Archie's law whereby the bulk resistivity of the aquifer depends on its porosity and on the resistivity of its hosted water.

The following limitations exist when trying to interpret bulk resistivity with water salinity, mostly in the present case, since we are dealing with one equation and two unknowns (porosity and water salinity). The available information in Israel relates only to storativities (connected porosities) of the rather shallow granular coastal aquifer and the carbonate Judea Group one. At least for carbonates, the total porosity might be higher than their storativity. Porosities are known to decrease at different rates with depth (i.e., Schmoker and Halley 1982; Ehrenberg and Nadeau 2005) but unfortunately very little is known regarding the deep units in the study area. Moreover, porosities obtained from analyses of well plugs are not necessarily representative due to scale dependency problems (Kafri and Goldman 2005).

It is interesting to note that the porosity effect is well exhibited in resistivity logs of relevant wells in the study area. The Hatira sandy formation of Lower Cretaceous age (see below), with rather high porosity, when containing water with roughly seawater salinity shows a fairly low resistivity. However, when a carbonate inter-layer occurs in the middle of this sandy unit its 
resistivity significantly increases due to its assumed lower porosity. This is well noticed for example in the logs of Betarim 1 and Sharsheret 1 wells.

Low resistivity units, such as the Saqiye Group sequence with a considerable thickness are known to "mask" the underlying sequence and to ascribe it as a continuous low resistivity layer (Kafri et al. 2007). Similarly, it was found that the Kidod Jurassic shale formation is considerably conductive apparently due to abundant amounts of pyrite. This is well exhibited as a very low resistivity zone in relevant well $\operatorname{logs}$ (i.e., Betarim 1, Hazerim 1, Sharsheret 1 wells). In some cases, this formation is detected as a low resistivity zone located between higher resistivity layers, whereas in other cases, a "masking" effect is recognized.

An important limiting factor was the penetration (more precisely exploration) depth of the TDEM method. In the present survey the depth varied between 1,000 and 2,000 $\mathrm{m}$ for the majority of the measurements with only a few exceptions reaching roughly $3,000 \mathrm{~m}$. Thus, the deeper brines of the DSB type known from subsurface hydrochemical data could not be detected. However, assuming their existence in depth and using their prescribed mean resistivity of $2 \Omega-\mathrm{m}$, the depth to their uppermost possible boundary was quantitatively estimated at each point.

It should be emphasized that a perfect sharp match between salinity and resistivity boundaries can be hardly achieved due to both a limited resolution of the TDEM measurements and to the fact that salinity boundaries are rarely sharp, but normally including thick transition zones.

\section{Results and Discussion}

\subsection{TDEM Results}

\subsubsection{General}

As mentioned above, the same bulk resistivity values may represent different contained water salinities, depending on porosity and depth dependent temperature. In the absence of detailed information, the interpretation is based on logical assumptions as well as on adjacent relevant hydrochemical results. In the case of the deep subsurface sequence, most of it consists of carbonates and an average fractional porosity of 0.1 was assumed and prescribed to it. Based on the above, the following conclusions can be made:

1) Bulk resistivities greater than $10 \Omega$-m represent fresh to slightly brackish water concentration. 2) Bulk resistivities between 3 and $10 \Omega-\mathrm{m}$ represent roughly seawater concentration. Within this range, one can also find brines of different concentrations, depending on porosity and depth. 3) The existence of diluted DSB in the deeper sequence, evidenced by hydrochemical information, is indicative of its existence at depth usually below $2 \mathrm{~km}$. For the assumed 0.1 porosity a roughly calculated $2 \Omega-\mathrm{m}$ bulk resistivity is obtained for such brines. At some sites such a resistivity was indeed measured in depth. At all other sites, where these brines were below the maximum exploration depth of the TDEM measurements, the $2 \Omega-$ $\mathrm{m}$ resistivity was prescribed to a deep layer underneath. The theoretical location of its uppermost possible boundary was calculated and shown on the TDEM cross-sections as dashed lines (Figs. 4, 5, and 6).

The results of the TDEM campaign are summarized herein as resistivity vs depths logs for each of the carried out 30 measurements, incorporated with the generalized geological information from the nearby wells. These data were used to prepare two parallel columnar resistivity cross-sections along the measured traverses. The cross- 


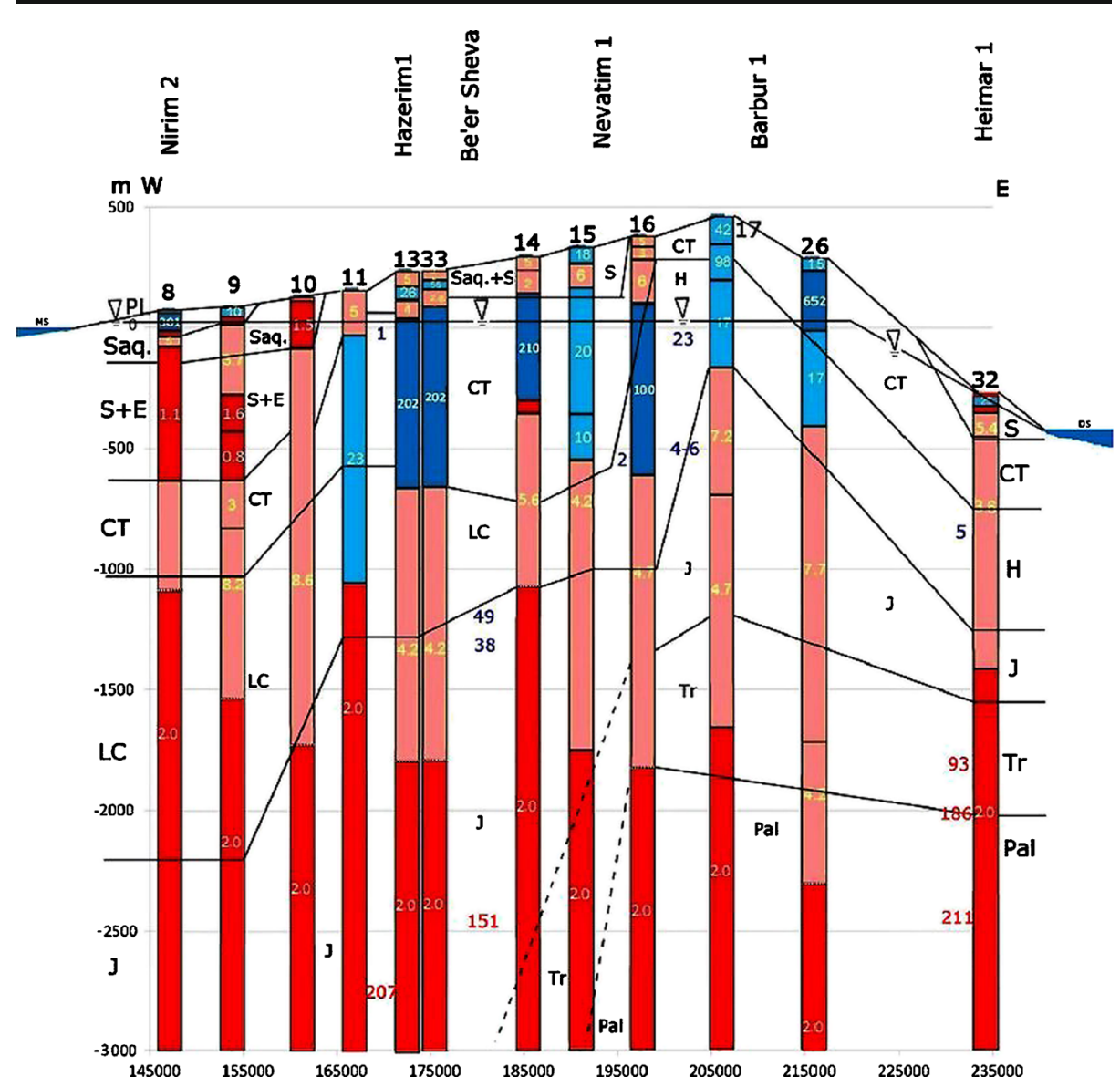

Fig. 4 The southern TDEM cross section

sections include the TDEM resistivity models, the main relevant geological units based on well logs, groundwater salinities in g/L TDS (in blue when $\mathrm{Na} / \mathrm{Cl}$ ratio matches the marine one and in red when it is below it). The approximate regional water table is also shown on the cross sections.

\subsubsection{The Southern Cross Section}

The southern cross section (Fig. 4) is located closer to the center of the Be'er Sheva Valley, and thus it seems to be less affected by the elevated structures and presumable higher groundwater levels in the north. It is assumed to be located entirely along the presumed path of the intruding seawater. Therefore, this cross section more adequately represents the suggested model.

It is noticed that the upper high resistivity fresh water body is hosted in the Judea Group (CT) and the lower Cretaceous (LC, H) aquifers. It extends along the entire cross section, whereby its lower boundary is controlled by the equipotential fresh water table. Parallel to the steep drop of the water table to the DSR base level east of measurement 26, the inclined interface between this body and the one underneath it rises toward the DSR and the thickness 


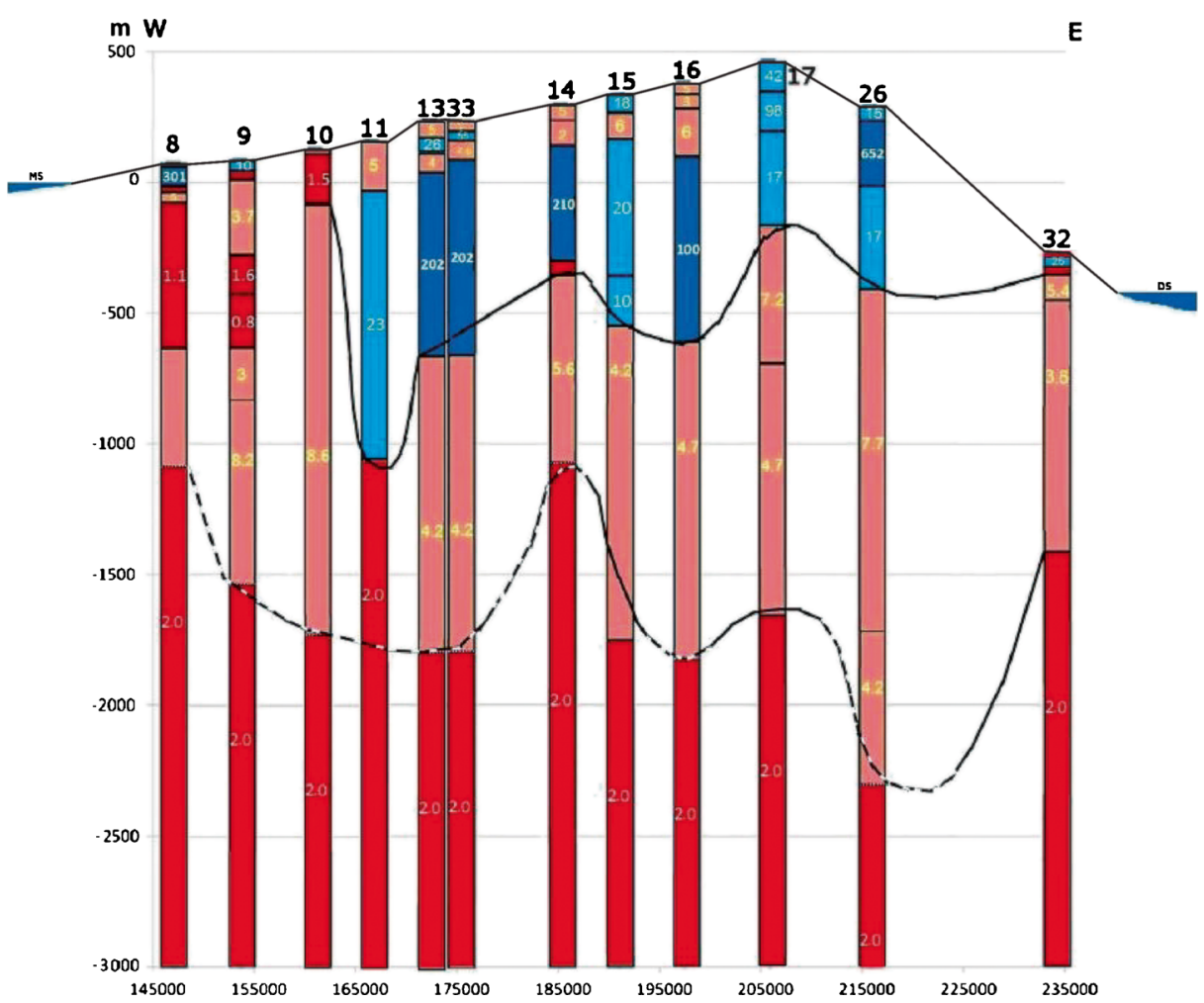

Fig. 5 A simplified southern TDEM cross section exhibiting the main resistivity units. The dashed line represents the uppermost possible appearance of the unit

of this body is reduced as expected. A reduction of the thickness of this body is noticed also at the west close to the Mediterranean base level caused by the effect of both the presumed inclined interface and the masking effect of the overlying Saqiye Group.

The underlying intermediate moderate resistivity body represents concentrations close to those of seawater and also extends along the entire cross section.

The very low resistivity body $(2 \Omega-\mathrm{m})$ underneath it, which assumingly represents the deep seated brines, was detected here by 4 measurements $(11,17,32)$ and its uppermost possible depth was calculated for the rest of the measurements that did not manage to reach the target. Here again, its upper boundary roughly exhibits the presumed inclined interfaces from the east and the west with two exceptions at measurements 11 and 14. Nevertheless, the anomalously shallow appearance of this boundary in those measurements seems to correlate with the Kidod Formation, and the top of the very low resistivity unit is thus expected to be at a deeper level in accordance with the rest of the cross Section. A simplified cross section thus exhibits the main resistivity units, whereby the dashed line represents the uppermost calculated possible appearance of the very low resistivity unit (Fig. 5).

\subsubsection{The Northern Cross-Section}

The northern cross section (Fig. 6) exhibits a less regular picture as compared to the southern one, being located on the northern margin of the valley. It is assumingly 


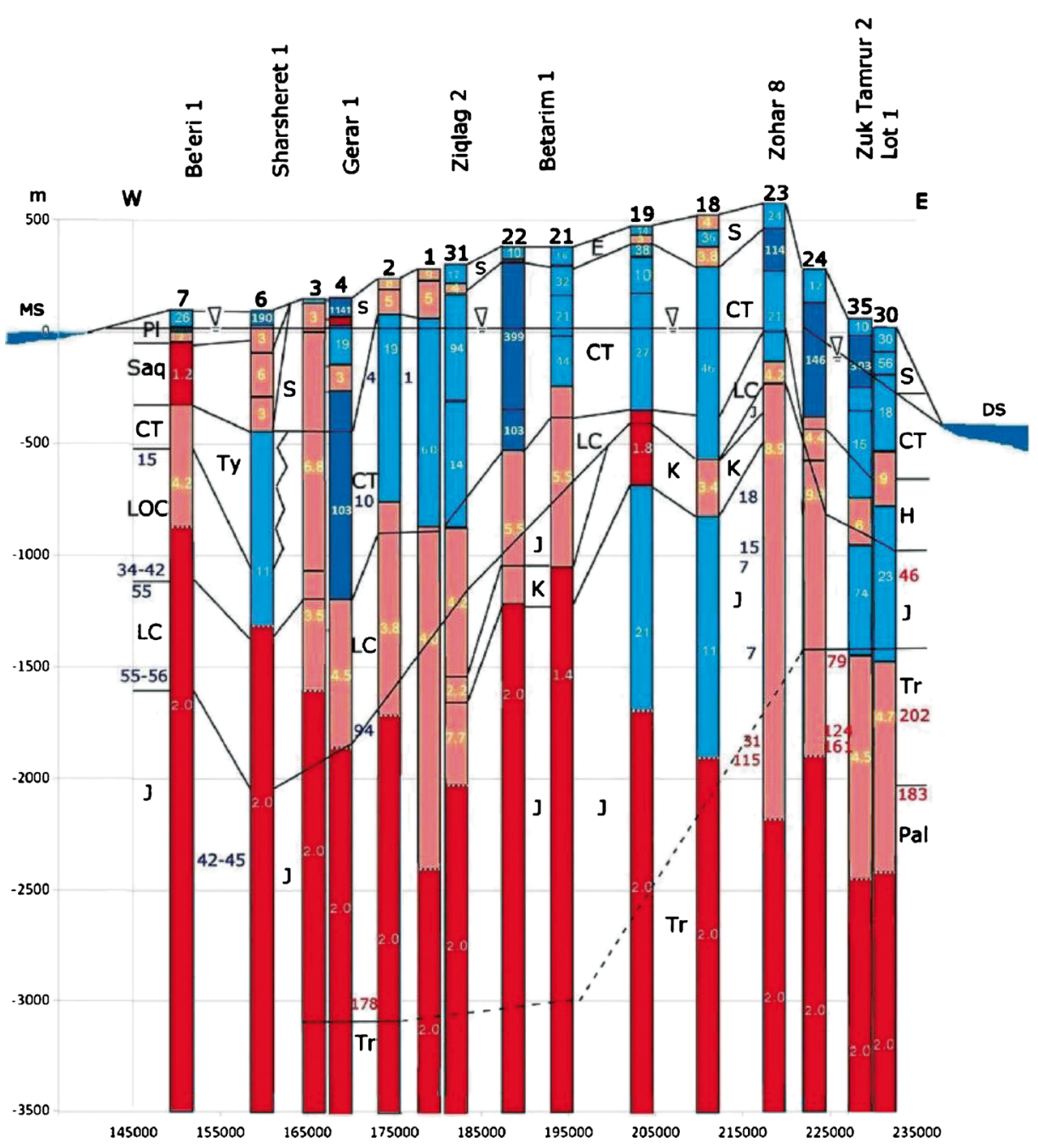

Fig. 6 The northern TDEM cross section

affected by the declining anticlines from the NE in its eastern portion. In the absence of groundwater level data there it is assumed that higher ones prevail there than along the southern cross section.

Similar to the southern cross section, an upper high resistivity fresh water body extends along the entire cross section, except for the western portion where it passes laterally to moderate to low resistivities representing seawater, brines and the low resistivity of the Saqiye Group. The underlying moderate resistivity body also extends along the entire cross section, representing salinities close to those of seawater. The lowermost very low resistivity body, which represents mostly concentrated brines, extends along the entire cross section. Its interface with the overlying moderate resistivity body is irregular, namely in some locations (measurements 21 and 22) it is higher than expected. This irregularity can be explained by the masking effect of the Kidod Formation in these locations. 
In measurements 18 and 19, the high resistivity body extends to a considerable depth with almost no moderate resistivity body. It is assumed herein that these locations, in the northern margin of the valley are characterized by higher groundwater levels, and thus, a deeper freshsaline water interface, and in addition, they are located outside the path of the seawater encroachment.

\subsection{Hydrochemical Results and Interpretation}

As mentioned before, the active groundwater system basically contains fresh groundwater in its upper portion, which drains both to the Mediterranean Sea base level in the west and to the DSR base level in the east. The lower portion of the system occupies concentrated or diluted brines. Between these water bodies, brackish water of various salinities exists, that might be a mixing product of different end members, namely fresh water, different brines and assumingly seawater.

The conservative $\mathrm{Na} / \mathrm{Cl}$ ratio was chosen herein to define the genetic origin of the different end members, as well as the compliance of this ratio in the mixing products with their assumed end members. The known $\mathrm{Na} / \mathrm{Cl}$ ratio of fresh meteoric water as well as of normal seawater is 0.82-0.86 (Kafri and Arad 1979). When seawater is concentrated by evaporation to brines of intermediate concentration, like the C-type brines, this ratio is still attained until the saturation concentration of approximately $350 \mathrm{~g} / \mathrm{L}$, similar to the DSB, when halite starts to be deposited. As a result, the brine becomes $\mathrm{Ca}$-chloride brine and the $\mathrm{Na} / \mathrm{Cl}$ ratio drops to 0.23 in the case of the DSB. In the case of post-halite brines, the ratio might be even lower (Starinsky 1974).

The TDS salinities and the $\mathrm{Na} / \mathrm{Cl}$ ratios of water samples obtained from wells in the study area, that are relevant to the interpretation of the TDEM results, are given in Table 2.

Figure 7 exhibits mixing curves diagram between the different candidate end members (fresh water, DSB and seawater) and their $\mathrm{Na} / \mathrm{Cl}$ ratios. In addition, the $\mathrm{Na} / \mathrm{Cl}$ ratios and salinities of the discussed water samples (Table 2) are plotted in order to check whether they comply with the different mixing curves. The following results are obtained:

a. All brackish water samples that attain a concentration between that of fresh water and that of 35 to $37 \mathrm{~g} / \mathrm{L}$ TDS corresponding to normal or Mediterranean seawater, respectively (samples $1,8,9,12,15,20,21$ ) exhibit a marine $\mathrm{Na} / \mathrm{Cl}$ ratio or greater than that, and seem to comply with a simple mixture between fresh water and seawater. One can argue that they could also stem from a mixing of fresh water with C-type brines, but the fact is that they exist also in the eastern part of the area (samples 14, 22-24, 27), where these brines, according to Starinsky (1974), do not exist.

b. Concerning the fresh water-DSB mixing curve, only a few samples close to the Dead Sea comply with a simple mixing of that type or close to it (samples 5,28), and some (samples $6,7)$ seem to be a mixing product of fresh water and post-halite brines of a lower $\mathrm{Na} / \mathrm{Cl}$ ratio. The drop of the $\mathrm{Na} / \mathrm{Cl}$ ratio along this curve starts to be significant even if a few percent of DSB exist in the mixture. Thus, a lower ratio serves as a signature to the existence of DSB.

c. The seawater-DSB mixing curve exhibits higher $\mathrm{Na} / \mathrm{Cl}$ ratio than those considered above and samples 29 and 30 collected even from the close vicinity of the Dead Sea comply with it.

d. Brackish waters between the concentration of fresh water and seawater that attain $\mathrm{Na} / \mathrm{Cl}$ ratios below the fresh water-seawater and above the fresh water-DSB curves, (samples 25, 26) seem to be mixing products of all three end members. Alternatively, they can be interpreted as a mixing product of fresh and seawater which was subjected to a baseexchange process. 
Table 2 Salinities, $\mathrm{rNa} / \mathrm{rCl}$ ratios and $\delta^{18} \mathrm{O}$ values in relevant oil wells

\begin{tabular}{|c|c|c|c|c|c|c|}
\hline Sample no. & Well & Depth (m) & Depth absolute (m) & Salinity (TDS) g/l & $\mathrm{r} \mathrm{Na} / \mathrm{r} \mathrm{Cl}$ & $\delta^{18} O_{0 / 00}$ \\
\hline 1 & Gerar 1 & 1190 & -1050 & 10 & 0.86 & \\
\hline 2 & $"$ & 2046 & -1900 & 94 & 0.82 & \\
\hline 3 & $"$ & 3239 & -3100 & 178 & 0.57 & \\
\hline 4 & $"$ & 3252 & -3110 & 139 & 0.62 & \\
\hline 5 & Lot 1 & 717 & -1070 & 46 & 0.32 & \\
\hline 6 & $"$ & 1268 & -1623 & 202 & 0.18 & -2 \\
\hline 7 & $"$ & 1683 & -2043 & 183 & 0.13 & -1.8 \\
\hline 8 & Sharsheret 1 & 2409 & -2306 & 42 & 0.87 & \\
\hline 9 & $"$ & 2670 & -2570 & 42 & 0.89 & \\
\hline 10 & $"$ & 2729 & -2630 & 55 & 0.88 & \\
\hline 11 & $"$ & 2759 & -2660 & 50 & 0.85 & \\
\hline 12 & Nirim 2 & 1142 & -1066 & 41 & 0.88 & \\
\hline 13 & Beeri 2 & 1235 & -1147 & 55 & 0.86 & \\
\hline 14 & Daya 1 & 1080 & -614 & 31 & 0.84 & -5.26 \\
\hline 15 & Be'er Sheva 1 & 1595 & -1337 & 37 & 0.9 & -1.93 \\
\hline 16 & $"$ & 2740 & -2482 & 151 & 0.7 & +0.47 \\
\hline 17 & Zuk Tamrur 2 & 1650 & -1547 & 79 & 0.66 & \\
\hline 18 & $"$ & 1971 & -1868 & 124 & 0.64 & \\
\hline 19 & $"$ & 1981 & -1878 & 161 & 0.60 & \\
\hline 20 & Barbur 1 & 1299 & -660 & 5.4 & 1.4 & -4.7 \\
\hline 21 & $"$ & 1517 & -860 & 4.5 & 1.2 & -6 \\
\hline 22 & Zohar 1 & 1161 & -533 & 17 & 0.82 & -3.4 \\
\hline 23 & Zohar 7 & 1243 & -913 & 7.5 & 1.1 & -7.4 \\
\hline 24 & $"$ & 1688 & -1360 & 6.4 & 1.3 & \\
\hline 25 & Zohar 8 & 1335 & -700 & 15 & 0.72 & -2.12 \\
\hline 26 & $"$ & 2542 & -1907 & 31 & 0.66 & -0.4 \\
\hline 27 & Heimar 1 & 589 & -880 & 5.2 & 1.3 & \\
\hline 28 & $"$ & 1459 & -1750 & 93 & 0.27 & \\
\hline 29 & $"$ & 1740 & -2030 & 186 & 0.32 & -0.9 \\
\hline 30 & $"$ & 2079 & -2370 & 211 & 0.31 & -0.26 \\
\hline
\end{tabular}

e. Brines with concentrations roughly between 50 and $100 \mathrm{~g} / \mathrm{L}$ (samples 2,10,11,13) from the western part of the area, with marine $\mathrm{Na} / \mathrm{Cl}$ ratios, represent the C-type brines or diluted brines.

f. Brines with concentrations roughly between 80 and $180 \mathrm{~g} / \mathrm{L}$ attain $\mathrm{Na} / \mathrm{Cl}$ ratios below those of fresh water, seawater or C-type brines (samples 3, 4, 16-19). In addition, their low $\mathrm{Na} / \mathrm{Cl}$ ratios are indicative of a DSB component. A simple mixing of DSB with fresh water is insufficient to obtain the $\mathrm{Na} / \mathrm{Cl}$ ratios of these mixtures. However, a mixture of DSB with seawater and fresh water in some proportion increases the $\mathrm{Na} / \mathrm{Cl}$ ratios toward the actual obtained ones, but still below them. It is thus assumed that an additional process of base- exchange of the involving fresh and seawater intermediate mixture end member could result in a higher $\mathrm{Na} / \mathrm{Cl}$ ratio as found here. It should be mentioned that this type of mixtures occurs both in the west and in the east close to the Dead Sea. 


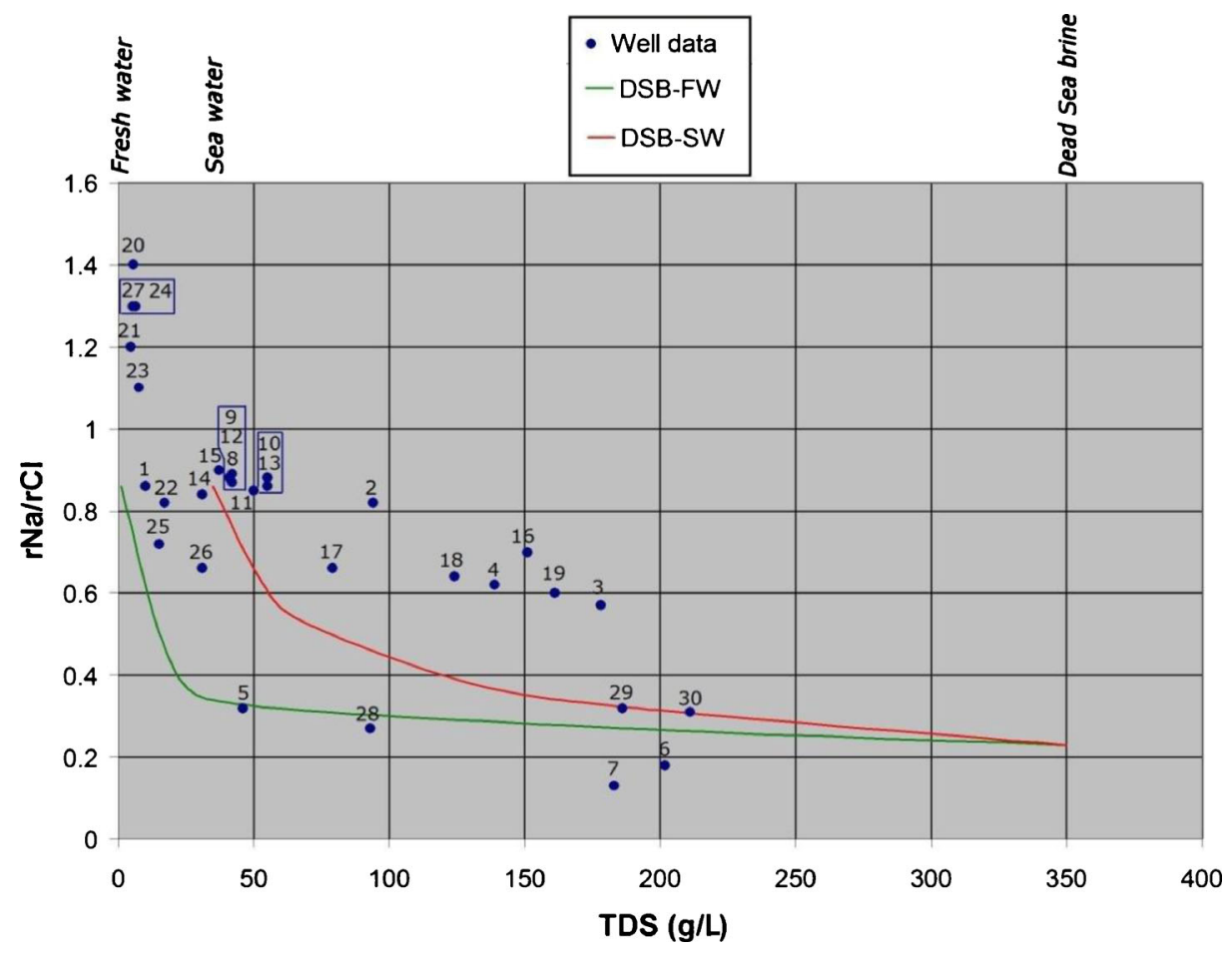

Fig. 7 A mixing diagram between the different potential end members

g. In all the possible scenarios described above a $\mathrm{Na} / \mathrm{Cl}$ ratio below the marine one serves as a signature to the existence of DSB as one of the components.

All the above considerations suggest a somewhat different model than that proposed in the past. In order to satisfy the mixing relationships, this model proposes an additional intruding seawater component between a fresh water body overlying solely R-type DSB in the east and C-type brine overlying the R-type brine in the middle and west.

Some sparce $\delta^{18} \mathrm{O}$ results, relevant to the study area were obtained (Fleischer et al. 1977) and incorporated in the study (Table 2).

A $\delta^{18} \mathrm{O}$-TDS mixing diagram of the possible end members is shown in Fig. 8. The $\delta^{18} \mathrm{O}$ prescribed values for the different end members, in per mil (after Gat and Dansgaard 1972) are: 0 for normal seawater (SW), 4 for Dead Sea brine (DSB), and -6 for meteoric fresh water (FW). A -8 value was prescribed for the paleo- slightly brackish water of the Nubian sandstone aquifer (NS), known in the subsurface of the central and eastern portion of the study area (Issar et al. 1972).

The $\delta^{18} \mathrm{O}$ results, when plotted on the diagram exhibit the following: a) Samples 29 and 30 that are close to the DSR and rather deep, fall on the FW-DSB mixing line which is in agreement with their low $\mathrm{Na} / \mathrm{Cl}$ ratios. b) Samples 6 and 7 from the same area, fall on the NS- DSB mixing line, which is also in agreement with their low $\mathrm{Na} /$ $\mathrm{Cl}$ ratios. c) Samples 20-23, 25 and 26 from the same area have salinities below or close to that of seawater. They fall on either the FW-SW or the NS-SW mixing line, in agreement with their high $\mathrm{Na} / \mathrm{Cl}$ ratios. d) Sample 14 is an exception since, 


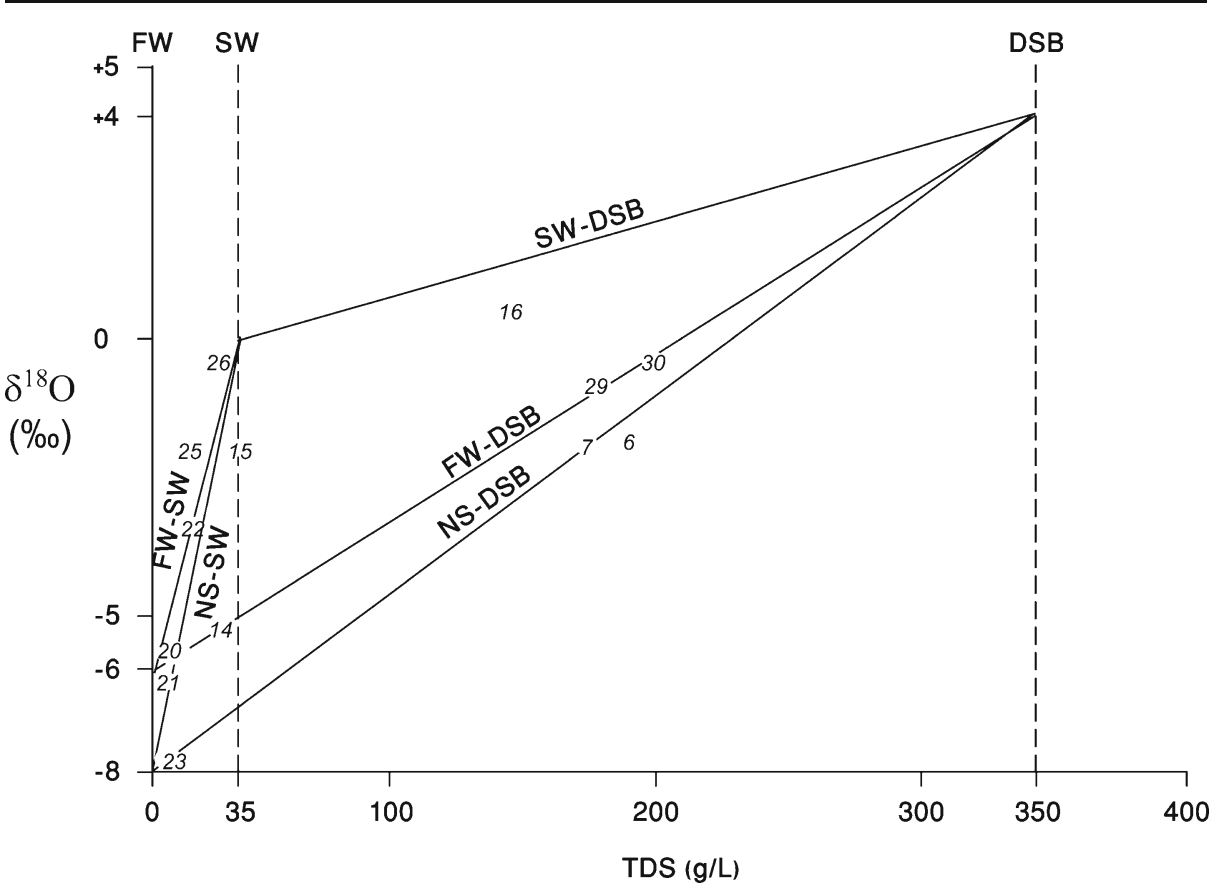

Fig. $8 \delta^{18} \mathrm{O}-\mathrm{TDS}$ mixing diagram of the possible fresh and saline water bodies end members

according to its $\mathrm{Na} / \mathrm{Cl}$ ratio, it should be a $\mathrm{FW}-\mathrm{SW}$ mixing product. However, for some yet unexplained reasons, it falls between the FW-DSB and the NS-DSB mixing line. e) Samples 15 and 16, obtained from the center of the study area, fall between SW-DSB and the FW-DSB mixing lines suggesting a mixture of those three end members.

\subsection{Subsurface Flow Modeling}

An attempt was made herein to use subsurface flow modeling to check the validity of the proposed hydrological setup regarding distribution of the different saline water bodies and flow directions. As already mentioned, modeling of the same study area has been done in the past (Stanislavsky and Gvirtzman 1999). In this study, the accepted hydrological setup of the fresh meteoric groundwater body, which overlies C-type brines in the west and westward density driven R-type brines from the DSR in the east, was modeled.

The present modeling was carried out using the FeFlow simulator (Diersch and Kolditz 2002). It differed from the previous modeling by enabling seawater encroachment from the sea in the west. This was done by prescribing higher conductivity $(\mathrm{K})$ values in the west rather than blocking this area by the known to be impermeable Talme Yafe Formation.

The aquifer was modeled using the Feflow code as a vertical 2D finite element densitydependent flow and transport model. The model consists of about 31,000 triangular finite elements, each element having a base size of about $200 \mathrm{~m}$. The model boundary conditions and hydraulic conductivity values $(\mathrm{K})$ are shown in Fig. 9. The Mediterranean Sea boundary in the west is defined as a specified head condition at an elevation of $0 \mathrm{~m}$ (asl) and a concentration of 


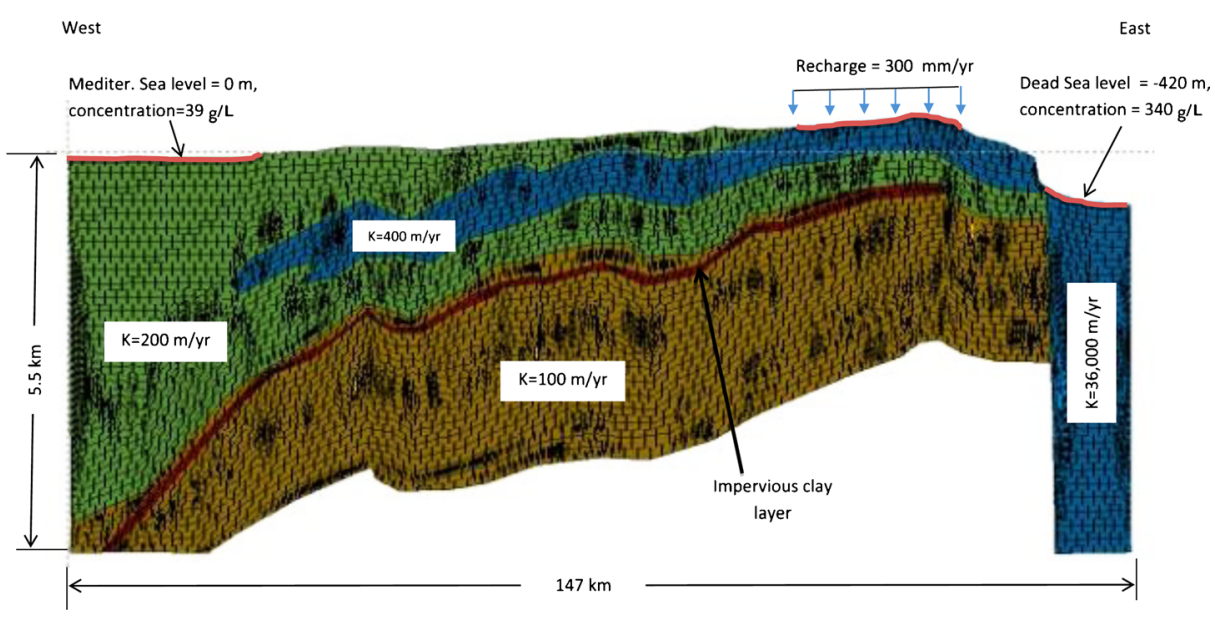

Fig. 9 The FeFlow model boundary conditions and the hydraulic conductivity $(\mathrm{K})$ values

$39,000 \mathrm{mg} / \mathrm{L}$ TDS. The density of the Mediterranean seawater is 1.025 . The specified head values of the sea boundary were adjusted to account for the density of the seawater. The Dead Sea boundary condition in the east was also defined as a specified head condition at an elevation of $420 \mathrm{~m}$ bsl. The Dead Sea water has a concentration of $340,000 \mathrm{mg} / \mathrm{L}$ and specific density of 1.23 . The specified head values of the Dead Sea boundary were also adjusted to account for the Dead Sea brine density. The recharge from rainfall of $300 \mathrm{~mm} /$ year was applied as a specified flux boundary condition along the outcrop region at the top of the model as shown in Fig. 6a. The model was run until the solution reached steady-state.

The results of the salinity distribution obtained by the model (Fig. 10) are indeed in agreement with the hydrochemical and the TDEM results. Moreover, the particle tracking, which is obtained from the modeling (Fig. 11), indeed shows the different flow directions as

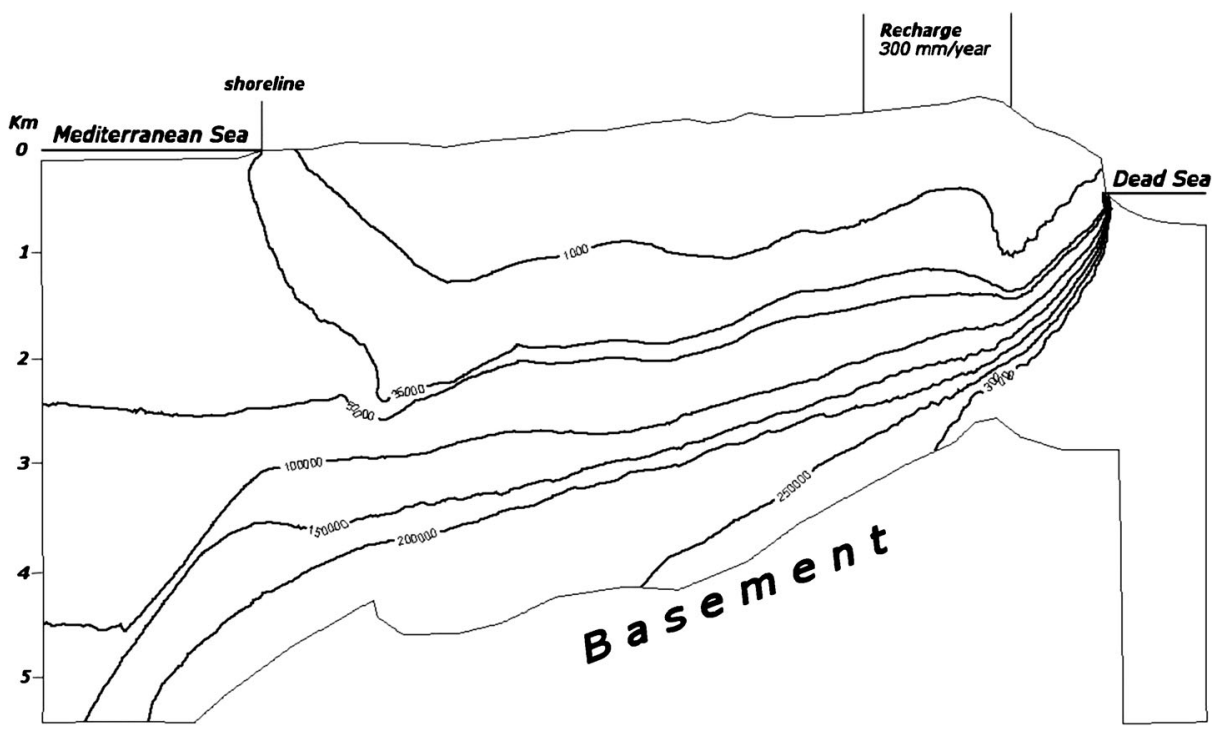

Fig. 10 Salinity distribution (g/L TDS) as obtained by the FeFlow model 


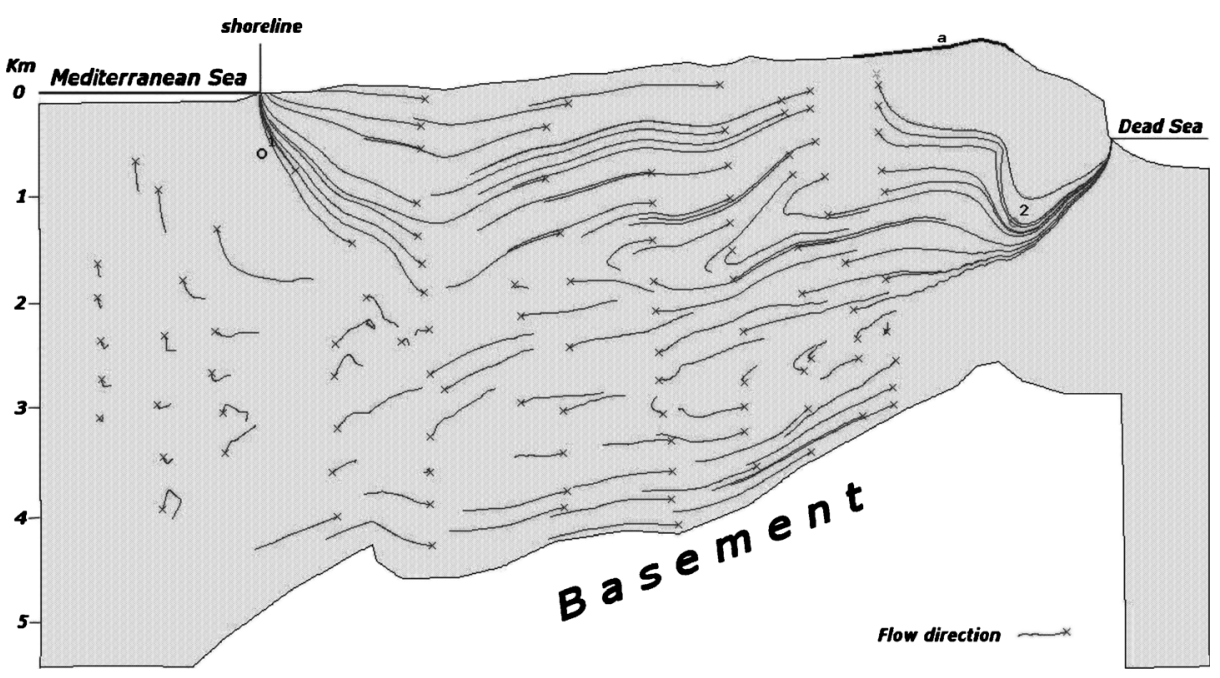

Fig. 11 Flow directions as obtained by particle tracking procedure of the FeFlow model

follows: fresh water flow from the divide to the east and west, underlain by a seawater flow all the way from the Mediterranean Sea in the west to the DSR base level in the east, and a lowermost back density driven brine flow to the west.

A model of current seawater intrusion to endorheic base levels below sea level, which constitute hyper-saline lakes or playas elsewhere in the world, was proposed by Kafri (1984)

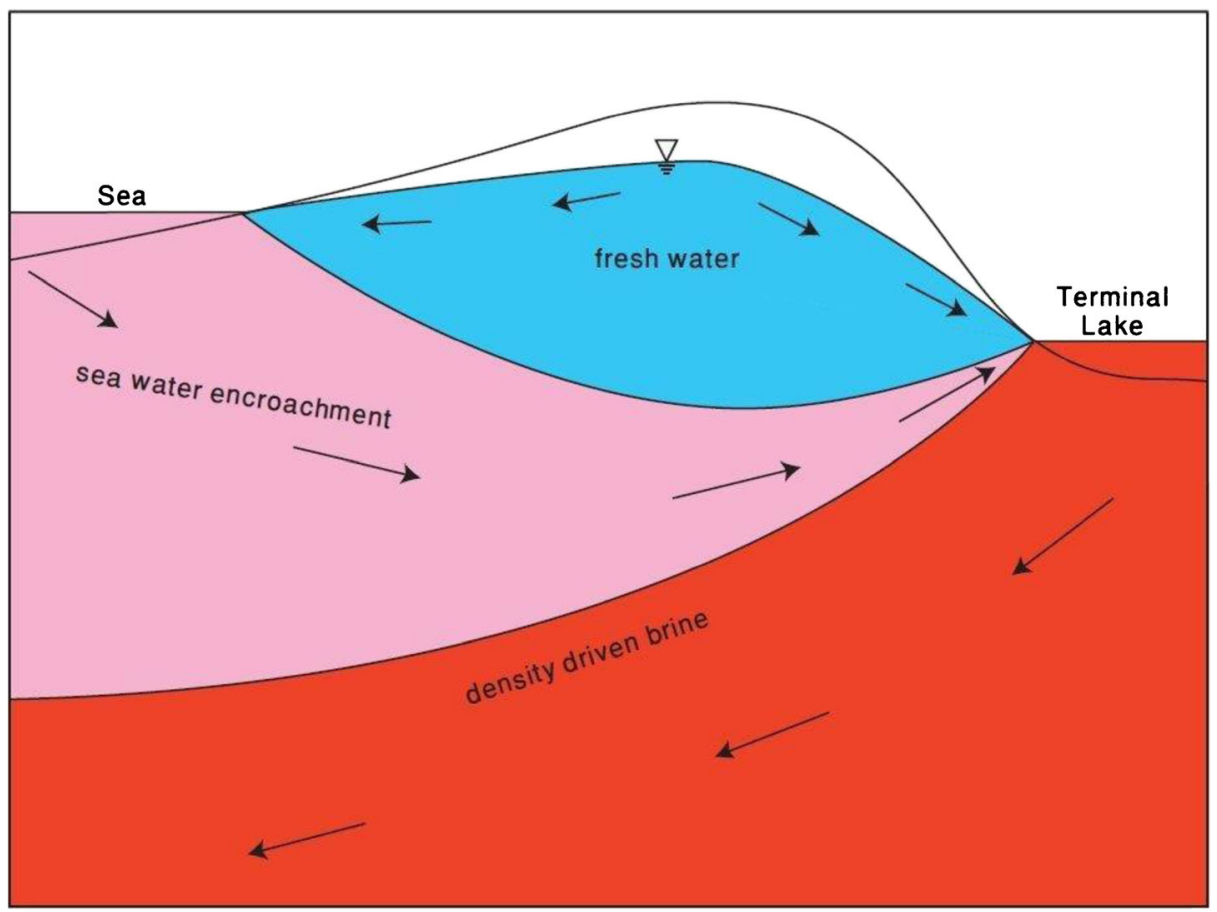

Fig. 12 A schematic salinity and flow direction model 
and Kafri and Yechieli (2010). Subsequently, two of the described cases, namely Lake Asal in East Africa and Lago Enriquillo in the Dominican Republic, were modeled by the FeFlow simulator (Kafri et al. 2013). Similar to the present case, a multiple salinity system was obtained beneath the upper fresh groundwater system of encroaching seawater all the way from the sea to the lower endorheic base level, and backward density driven brines underneath it to the opposite direction as shown schematically in Fig. 12.

\section{Conclusions}

The TDEM measurements were apparently not sufficiently deep enough to detect brines at all deep locations. In addition, the TDEM method has a high ambiguity in defining groundwater salinity from measured resistivities in deep carbonate aquifers as compared to shallow granular ones. This is caused by both much greater variability of hydraulic parameters involved and by significantly scarcer borehole information available for calibration. The above limitations of geophysical methods were minimized to a certain extent in the present study by incorporating hydrochemical and hydrological information to obtain the following hydrogeological configuration and model for the study area.

The groundwater system along the Be'er Sheva Valley between the Mediterranean Sea and the Dead Sea consists of the following resistivity/salinity units from top to bottom:

a) An upper high resistivity fresh to somewhat brackish water body, which flows to the western Mediterranean and eastern DSR base levels. This water body represents the Judea Group and the Lower Cretaceous aquifers.

b) Below the upper unit, a moderate resistivity body is detected, whose origin cannot be uniquely determined by TDEM measurements. According to hydrochemical parameters, the body represents a triple component sequence including deep seated brines, seawater intrusion from the west and fresh water.

c) A lowermost very low resistivity body representing C-type and R-type brines or diluted brines, whereby the latter are density driven from the DSR westward. This is deduced mainly from hydrogeological and hydrochemical data. The TDEM results directly supported these data at several sites, whereas at the rest, the estimated minimum depth to the top of the lowermost very low resistivity layer does not contradict the suggested model.

This triple system model is also supported by a FeFlow hydrological simulator. This model was found to match similar hydrogeological setups elsewhere in the world.

Acknowledgments The project was initiated and funded by the Hydrological Service of Israel under the supervision and heartily support of the late Vladi Friedman, who passed away in January 2012. The TDEM field survey was carried out by the Geophysical Institute of Israel under the supervision of Dr. Alex Zaharkin, Novosibirsk, Russia.

\section{References}

Burg A, Gavrieli I, Bein A, Friedman V (2006) The YARTAN monitoring project. Chemical and isotopic compositions in monitoring boreholes and chosen wells. Geol Serv Isr Rep GSI/26/2005 (In Hebrew) 28 p

Constable SC, Parker RL, Constable CG (1987) A practical algorithm for generating smooth models from electromagnetic sounding data. Geophysics 52:289-300 
Diersch H-JG, Kolditz O (2002) Variable-density flow and transport in porous media: approaches and challenges. Adv Water Resour 25:899-944

Ehrenberg SN, Nadeau PH (2005) Sandstone vs. carbonate petroleum reservoirs: a global perspective on porosity-depth and porosity -permeability relationships. Am Assoc Pet Geol Bull 89:435-445

Fleischer E, Goldberg M, Gat JR, Magaritz M (1977) Isotopic composition of formation waters from deep drilling in southern Israel. Geochim Cosmochim Acta 41:511-525

Gat JR, Dansgaard W (1972) Stable isotope survey of the fresh water occurrences in Israel and the northern Jordan Rift Valley. J Hydrol 16:177-212

Goldman M, Kafri U (2004) The use of the time domain electromagnetic (TDEM) method to evaluate porosity of saline water saturated aquifers. 18th Salt Water Intrusion Meeting (SWIM) selected papers. Cartagena 2004. The Institute of Geology and Mineralogy of Spain Publications 15:327-340

Goldman M, Kafri U (2006) Hydrogeophysical applications in coastal aquifers. In: Vereecken H, Binley A, Cassiani G, Revil A, Titv K (eds.) Appl hydrogeophys. Springer, Amsterdam, pp 233-254

Goldman M, Arad A, Kafri U, Gilad D, Melloul A (1989) Detection of freshwater/seawater interface by the time domain electromagnetic (TDEM) method in Israel. Nat Tijdschr 70:39-344

Goldman M, Kafri U, Yechieli Y (2003) Application of the TDEM method for studying groundwater salinity in different coastal aquifers in Israel. In: Lopez-Geta JA, de Dios Gomes J, de la Orden JA, Ramos G, Rodriguez L (eds.) "Coastal aquifers intrusion technology: Mediterranean countries". The Institute of Geology and Mineralogy of Spain (IGME), Madrid, p 45-56

Issar A, Bein A, Michaeli A (1972) On the ancient water of the upper Nubian sandstone aquifer in central Sinai and southern Israel. J Hydrol 17:353-374

Kafri U (1984) Current subsurface seawater intrusion to base levels below sea level. Environ Geol Water Sci 6: 223-227

Kafri U, Arad A (1979) Current subsurface intrusion of Mediterranean seawater. A possible source of groundwater salinity in the Rift Valley system, Israel. J Hydrol 44:267-287

Kafri U, Goldman M (2005) The use of the time domain electromagnetic (TDEM) method to delineate saline groundwater in granular and carbonate aquifers and to evaluate their porosity. J Appl Geophys 57:167-178

Kafri U, Goldman M (2006) Are the lower subaquifers of the Mediterranean coastal aquifer of Israel blocked to seawater intrusion? Results of a TDEM (time domain electromagnetic) study. Isr J Earth Sci 55:55-68

Kafri U, Goldman M (2013) The significance of the findings of diluted seawater in the Yoqneam 7 borehole east of the regional groundwater divide. Isr Geol Soc Annu Meet Abstracts. Akko. p 101

Kafri U, Yechieli Y (2010) Groundwater base level changes and adjoining hydrological systems. Springer, Berlin Heidelberg. doi:10.1007/978-3-642-13944-4

Kafri U, Goldman M, Lang B (1997) Detection of subsurface brines, freshwater bodies and the interface configuration in-between by the time domain electromagnetic method in the Dead Sea Rift, Israel. Environ Geol 31:42-49

Kafri U, Goldman M, Lyakhovsky V, Scholl C, Helwig S, Tezkan B (2007) The configuration of the fresh-saline groundwater interface within the regional Judea Group carbonate aquifer in northern Israel between the Mediterranean and the Dead Sea base levels as delineated by deep geoelectromagnetic soundings. J Hydrol 344:123-134

Kafri U, Goldman M, Levi E (2008) The relationship between saline groundwater within the Arava Rift Valley in Israel and the present and ancient base levels as detected by deep geoelectromagnetic soundings. Environ Geol 54:1435-1445

Kafri U, Shalev E, Lyakhovsky V, Wollman S, Yechieli Y (2013) Numerical modeling of seawater intrusion into endorheic hydrological systems. Hydrogeol J. doi:10.1007/s10040-013-0972-5

Levi E, Goldman M, Hadad A, Gvirtzman H (2008) Spatial delineation of groundwater salinity using deep time domain electromagnetic geophysical measurements: a feasibility study. Water Resour Res 44, W12404. doi: 10.1029/2007WR006459

Nativ R (1984) The water potential of the deep Jurassic to Paleozoic aquifers in the Negev, Israel. Ph D thesis, Ben Gurion Univ Beer Sheva. 311p. (In Hebrew)

Natural Resources Development (1999) The study of the western boundary of the Yarqon- Taninim aquifer. Interim report. NR/270/99 23p (in Hebrew)

Schmoker JW, Halley RB (1982) Carbonate porosity versus depth: a predictable relation for South Florida. Am Assoc Pet Geol Bull 37:2498-2512

Shahar J (1994) The Syrian arc system: an overview. Palaeogeogr Palaeoclimatol Palaeoecol 112:125-142, Israel. Solid Earth Discuss 3:431-452

Stanislavsky E, Gvirtzman H (1999) Basin-scale migration of continental-rift brines: paleohydrologic modeling of the Dead Sea basin. Geology 27:791-794

Starinsky A (1974) Relationship between Ca-chloride brines and sedimentary rocks in Israel. Ph D thesis, Hebr Univ Jerusalem. 176 p. (In Hebrew) 